\title{
Association between maxillary transverse discrepancy and occurrence of potentially impacted maxillary canines in mixed dentition patients
}

\author{
Farhana Ghaffar \\ Ekangala Clinic, Gauteng, South Africa \\ Rashna Hoshang Sukhia \\ Aga Khan University, rashna.aga@aku.edu \\ Mubassar Fida \\ Aga Khan University, mubassr.fida@aku.edu
}

Follow this and additional works at: https://ecommons.aku.edu/

pakistan_fhs_mc_surg_dent_oral_maxillofac

Part of the Dentistry Commons, and the Surgery Commons

\section{Recommended Citation}

Ghaffar, F., Sukhia, R. H., Fida, M. (2019). Association between maxillary transverse discrepancy and occurrence of potentially impacted maxillary canines in mixed dentition patients. International Orthodontics, 17(3), 554-561.

Available at: https://ecommons.aku.edu/pakistan_fhs_mc_surg_dent_oral_maxillofac/115 


\section{AUTHOR QUERY FORM}

\begin{tabular}{|c|c|c|}
\hline 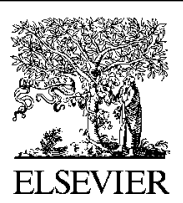 & $\begin{array}{l}\text { Journal: ORTHO } \\
\text { Article Number: } 394\end{array}$ & Please e-mail your responses and any corrections to: \\
\hline
\end{tabular}

Dear Author,

Please check your proof carefully and mark all corrections at the appropriate place in the proof (e.g., by using on-screen annotation in the PDF file) or compile them in a separate list. Note: if you opt to annotate the file with software other than Adobe Reader then please also highlight the appropriate place in the PDF file. To ensure fast publication of your paper please return your corrections within 48 hours.

For correction or revision of any artwork, please consult http://www.elsevier.com/artworkinstructions.

Any queries or remarks that have arisen during the processing of your manuscript are listed below and highlighted by flags in the proof. Click on the 'Q' link to go to the location in the proof.

\begin{tabular}{|c|c|}
\hline $\begin{array}{l}\text { Location in } \\
\text { article }\end{array}$ & $\begin{array}{c}\text { Query / Remark: click on the Q link to go } \\
\text { Please insert your reply or correction at the corresponding line in the proof }\end{array}$ \\
\hline $\begin{array}{l}\text { Q1 } \\
\text { Q2 }\end{array}$ & $\begin{array}{l}\text { The author names have been tagged as given names and surnames (surnames are highlighted in teal } \\
\text { color). Please confirm if they have been identified correctly. } \\
\text { Correctly acknowledging the primary funders and grant IDs of your research is important to ensure } \\
\text { compliance with funder policies. We could not find any acknowledgement of funding sources in your } \\
\text { text. Is this correct? } \\
\text { Have we correctly interpreted the following funding source(s) and country names you cited in your } \\
\text { article:University Research Council Grant from the Aga Khan University, Karachi, Pakistan? }\end{array}$ \\
\hline & $\begin{array}{l}\text { Please check this box or indicate your approval if } \\
\text { you have no corrections to make to the PDF file }\end{array}$ \\
\hline
\end{tabular}

Thank you for your assistance. 


\section{Association between maxillary transverse discrepancy and occurrence of potentially impacted maxillary canines in mixed dentition patients}

Q1 Farhana Ghaffar ${ }^{1}$, Rashna Hoshang Sukhia ${ }^{2}$, Mubassar Fida ${ }^{2}$

Available online:

Keywords

Transverse maxillary

discrepancy

canine impaction

Mixed dentition
Mots clés

Déficit transversal

maxillaire

Inclusion canine

Denture mixte

\author{
1. Ekangala Clinic, Gauteng, South Africa \\ 2. The Aga Khan University Hospital, Karachi, Pakistan \\ Correspondence: \\ Rashna Hoshang Sukhia, The Aga Khan University Hospital, Section of Dentistry, \\ Department of Surgery, P.0 Box 3500, Stadium Road, 74800 Karachi, Pakistan. \\ rashna_aga@yahoo.com
}

\section{Summary}

Objective > The aim of this study was to determine the association between transverse maxillary discrepancy and occurrence of potentially impacted maxillary canines in mixed dentition patients. Material and methods > This cross-sectional analytical study was conducted on 85 Pakistani subjects (32 males and 53 females) aged between 8 to 13 years, having good quality orthopantomographs and dental casts. Maxillary transverse discrepancy was assessed by subtracting the mandibular intermolar width from the maxillary intermolar width on dental cast. Maxillary lateral incisors and canines were traced from orthopantomographs, and canines were placed into sector classification. Chi-square test was used to determine the difference in the occurrence of potentially impacted maxillary canines between patients with maxillary transverse discrepancy and patients without maxillary transverse discrepancy.

Results > There was no significant difference seen in the occurrence of impacted maxillary canines in patients with and without maxillary transverse discrepancy in mixed dentition patients.

Conclusion > Patients with maxillary transverse discrepancy may not be at a higher risk of palatal canine impaction. Radiological presence of canine in sector II, III and IV, pose a higher risk of canine impaction.

\section{Résumé}

Lien entre déficit transversal du maxillaire et incidence des canines maxillaires incluses chez les patients en denture mixte

objectif > Le but de cette étude était de déterminer le lien entre un déficit transversal du maxillaire et l'incidence des canines maxillaires incluses chez les patients en denture mixte. 
To cite this article: Ghaffar F, et al. Association between maxillary transverse discrepancy and occurrence of potentially impacted maxillary canines in mixed dentition patients. International Orthodontics (2019), https://doi.org/10.1016/j.ortho.2019.06.016

F. Ghaffar, R.H. Sukhia, M. Fida

Matériel et méthodes > Cette étude analytique transversale a été menée sur 85 sujets pakistanais (32 hommes et 53 femmes) âgés de 8 à 13 ans, dont les radiographies panoramiques et les empreintes dentaires étaient de bonne qualité. Le déficit transversal du maxillaire a été calculé en mesurant la différence entre les largeurs intermolaires maxillaires et mandibulaires sur les moulages. Les incisives latérales et les canines maxillaires ont été tracées à partir des panoramiques, et les canines ont été classées par secteur. Le test du $\chi^{2}$ a été utilisé pour comparer l'incidence des canines maxillaires incluses chez les patients avec et sans déficit transversal maxillaire.

Résultats > Aucune différence significative n'a été observée concernant l'incidence des canines maxillaires incluses chez les patients en denture mixte avec ou sans déficit transversal du maxillaire.

Conclusion > Les patients ayant un déficit transversal du maxillaire peuvent ne pas présenter un risque plus élevé d'inclusion palatine des canines. La présence radiologique des canines dans les secteurs II, III et IV constitue un risque plus élevé d'inclusion canine.

\section{Introduction}

Q2 The ectopic eruption and impaction of maxillary permanent canines is a frequently encountered clinical problem. Maxillary canine is the most commonly impacted tooth in the dental arch after the third molar [1-5]. Its impaction has been reported in approximately two percent of the patients reporting for orthodontic treatment $[2,6]$. Maxillary canines are ten times more commonly impacted than their mandibular counterparts $[7,8]$. Palatal impactions (85\%) are reported to be more common than the labial (15\%) impactions [1,2,9-11], with unilateral impactions being more prevalent than the bilateral impactions [12]. Similarly, maxillary canine impaction is more frequently seen in females and is commonly seen in association with peg-shaped or missing lateral incisors [13].

From a developmental point of view, no tooth is more interesting than the maxillary canine, as it develops lateral to the piriform fossa, and follows a long tortuous path to erupt into the occlusal plane only after the eruption of adjacent teeth [14]. Crowns of maxillary permanent canines are in close relation with the roots of the lateral incisors thus making an orthodontist cautious to keep an eye on early correction of flared and distally tipped lateral incisors and to prevent impaction of canines or resorption of the roots of lateral incisors [15].

Impacted canines may be caused due to systemic condition like some endocrine disorder or radiation exposure or more commonly due to lack of space, delayed or early shedding of deciduous canine, cleft of alveolus, ectopic position of tooth germ, lack of development or deviation in morphology of maxillary lateral incisor [2,16-18].

Genetic factors including race, gender and supernumerary teeth may also play an important role in its etiology. Impacted canines are reported more frequently in females and Caucasians with palatal canine impaction being more predominant in Caucasians as compared to Asians $[7,12,17]$. Congenitally missing teeth have been reported in about 33\% of patients having impacted canines [19].

Thorough clinical and radiographic examination can aid in early detection of the possible impaction of maxillary canines even in patients aged 9 to 10 years. Clinically, buccal bulge palpated on digital examination above the primary canine root, in an apical area has been recommended as a tool for early diagnosis. During the clinical examination, the permanent lateral incisors should also be carefully checked. Abnormal position or angulation of lateral incisors may also indicate towards a mesially drifted canine which in turn may become impacted.

An additional complication regarding location of the impaction is the preponderance of palatal impactions over buccal impactions with a reported ratio of 3:1 [20]. Labial displacement of maxillary canine is usually due to inadequate dental arch space which delays eruption, but rarely leads to an impaction [14]. However, palatally impacted canines are reported to occur in patients with adequate arch length, along with other dental anomalies, like missing and malformed teeth $[4,5,18]$.

Transverse maxillary deficiency is one of the most frequent findings in primary and mixed dentitions. A transpalatal width of $36-39 \mathrm{~mm}$ in the maxillary arch may accommodate teeth without spacing or crowding, however with a maxillary arch width less than $31 \mathrm{~mm}$ crowding may be present [21] McConnell et al. [22] reported presence of impacted maxillary canines in patients having a narrow maxillary anterior dental arch.

Radiographs such as orthopantomograms, occlusal films, periapical films and lateral cephalograms are usually used to aid in diagnosing the canine position. The mesiodistal position and angulation of the canine crown on an orthopantomogram can possibly predict treatment success $[6,10,23]$. Ericson and Kurol [9] reported less likelihood of eruption of a more mesially positioned canine crown following extraction of deciduous canine. Power and Short [10] reported a decreased chance of 
Association between maxillary transverse discrepancy and occurrence of potentially impacted maxillary canines in mixed dentition patients

eruption of maxillary canine with an angulation greater than $31^{\circ}$ to the midline. Lindauer et al. [23] determined the probability of impaction based on the location of the canine cusp tip in one of the four sectors, regarding its relationship to the adjacent lateral incisor. Jung et al. [24] in their study reported that canines in panoramic Sectors I, II and III were more frequently in a labial position on the CBCT (cone beam computed tomography), however canines in Sector IV were seen to be in the mid alveolus position.

Maxillary canine impaction is complex in its aetiology, localisation, response to preventive treatment and prediction. Early diagnosis and detection of a potentially impacted maxillary canine reduces the need for complicated orthodontic treatment which involves substantial time and cost. Alessandri et al. [14] reported that interceptive treatment like extraction of deciduous maxillary canine and first molar shows significant improvement in intrabony position of impacted canines. Baccetti et al. [15] in their randomized controlled trial showed that treatment with transpalatal arch was as effective as treatment with combination of rapid palatal expansion and transpalatal arch in cases with palatally displaced maxillary canines. The aim of this study was to determine the association between transverse maxillary discrepancy and occurrence of potentially impacted maxillary canines in mixed dentition patients. A secondary objective was to determine the distribution of impacted maxillary canines according to sector. The evaluation of potentially impacted maxillary canines at an early stage in subjects with maxillary transverse deficiency will be helpful in orthodontic diagnosis and treatment planning.

\section{Methods}

The present study was a cross-sectional comparative study carried out using pretreatment records of patients attending the Orthodontic Clinic, from 2002 to 2008. Pakistani patients aged between 8 to 13 years, having good quality orthopantomographs (OPG) and dental casts were included. The exclusion criteria were as follows: patients with missing teeth or dental anomalies like malformed teeth, transpositions and impactions, systemic diseases affecting growth and development and history of previous orthodontic and/or orthopaedic treatment. In our study, mixed dentition was defined as "a period in which the maxillary canines were unerupted and at least the primary second molars were retained". Maxillary transverse discrepancy was calculated by subtracting the mandibular intermolar (IM) width of the arch from the maxillary intermolar (IM) width. IM width was measured with a digital vernier caliper (Micrometre 400-044, Apogee electronic kits and tools, resolution of 0.0005 in $/ 0.01 \mathrm{~mm}$ ). Figure 1 shows the measurement of maxillary and mandibular inter molar widths. The maxillary IM width was measured as "the distance between the mesio-lingual cusp tips of the right and left first permanent molars". The mandibular IM width was measured as "the distance between the central fossae of the right and left first permanent molars". The difference between the maxillary and mandibular IM widths was then recorded and patients having negative difference in intermolar widths were placed in Group I i.e. maxillary transverse discrepancy group, whereas patients with positive difference in intermolar widths were placed in Group II i.e. without maxillary transverse discrepancy group. The maxillary lateral incisors and canines were traced on an acetate sheet from the panoramic radiographs of both the groups. The traced lateral incisors and canines were analysed using the Sector Classification [23] as shown in figure 2. According to sector classification, "sector I is the area distal to a line tangent to the distal heights of contour of the lateral incisor crown and root. Sector II is mesial to sector I but distal to a line bisecting the mesiodistal dimension of the lateral incisor along the long axis. Sector III is mesial to sector II but distal to a line tangent to the mesial heights of contour of the lateral incisor crown and root. Sector IV included all areas

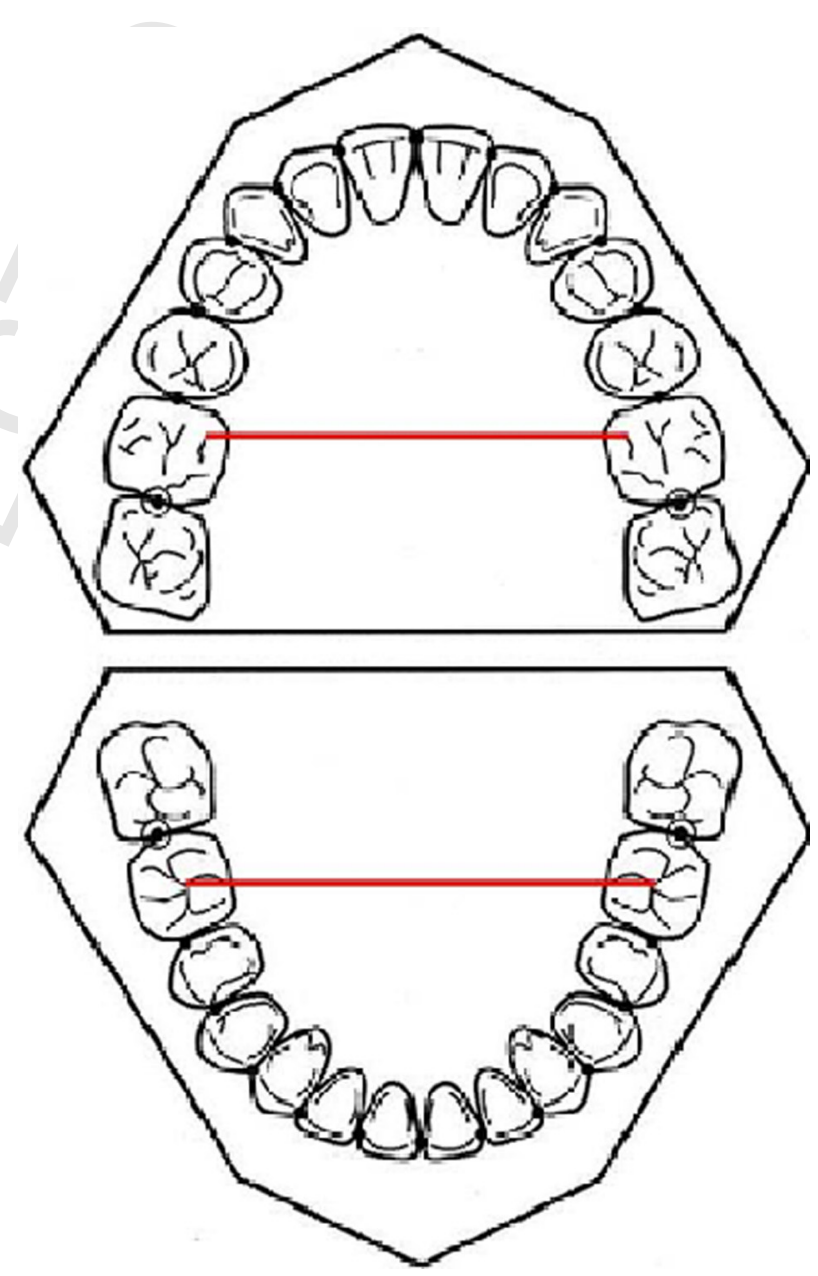

FIGURE 1

Measurements of maxillary and mandibular inter molar widths 


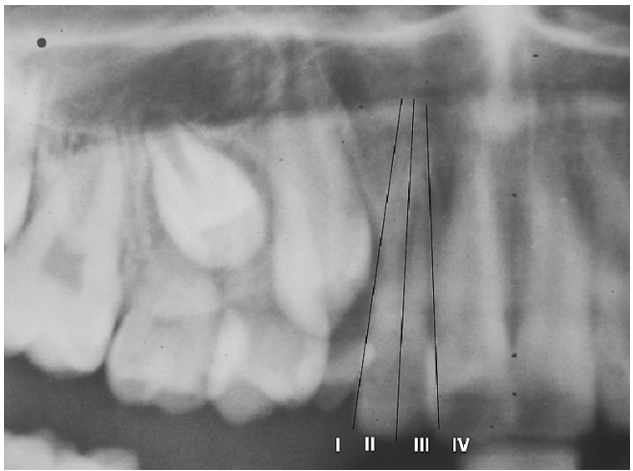

FIGURE 2

\section{Sectors classification}

mesial to sector III". Patients with sector I were classified as having no potential maxillary canine impaction, whereas, patients falling in sector II, III and IV were classified as having potentially impacted maxillary canines [23].

Data analysis were analyzed using the Statistical Package for Social Sciences for Windows version 16.0 (SPSS Inc., Chicago, Illinois, USA). Descriptive statistics were used to calculate means and standard deviations of age, maxillary intermolar widths and mandibular intermolar widths. Frequency was calculated for gender and potentially impacted canine. The mean age for subjects in Group I (maxillary transverse discrepancy) was $9.96 \pm 1.25$ and for Group II subjects (no maxillary transverse discrepancy) was $10.22 \pm 1.35$. The mean maxillary and mandibular intermolar widths for Group I subjects were $38.8 \pm 2.29$ and $40.7 \pm 2.37$ respectively. For the Group II subjects the mean maxillary and mandibular intermolar widths were $40.5 \pm 2.34$ and $39.8 \pm 2.51$ respectively. $41.3 \%$ of group I subjects were male and $58.7 \%$ were female. However, in Group II 33.3\% of subjects were male and $66.7 \%$ were females. The percentage of unilateral canine impactions in Group I was $45.6 \%$ and in Group II was 35.9\%. Bilateral canine impactions in Group I were reported to be $13 \%$ and in Group II 25.6\%.
Chi-square test was used to determine the difference in the occurrence of potentially impacted maxillary canines between Group I (patients with maxillary transverse discrepancy) and Group II (patients without maxillary transverse discrepancy). Chi-square test was also used to assess the frequency of type of impaction, unilateral or bilateral in both the groups. All statistical tests were two tailed and $P$-value of $<0.05$ was considered to be significant. Twenty patients were randomly selected and their casts and orthopantomograms were measured again after a period of one month to rule out measurement error. Pearson's correlation was used to assess the correlation amongst the two readings and a statistically significant correlation was observed between the two measurements $(r=0.898, P<0.05)$.

\section{Results}

A total of 85 subjects ( 32 males and 53 females) meeting the selection criteria were included. Mean age for Group I (with maxillary transverse discrepancy) was $9.96 \pm 1.25$ years whereas for Group II (without maxillary transverse discrepancy) was $10.22 \pm 1.35$ years. In Group I (with maxillary transverse discrepancy), the mean maxillary IM width was 38.8 $\pm 2.29 \mathrm{~mm}$ and the mean mandibular IM width was 40.7 $\pm 2.37 \mathrm{~mm}$ with a mean difference between maxillary and mandibular IM width of $-1.9 \pm 1.37 \mathrm{~mm}$. In Group II (without maxillary transverse discrepancy), the mean maxillary IM width was $40.5 \pm 2.34 \mathrm{~mm}$ and the mean mandibular IM width was $39.8 \pm 2.51 \mathrm{~mm}$ with a mean difference between maxillary and mandibular IM width of $0.8 \pm 0.52 \mathrm{~mm}$.

Table I depicts the distribution of maxillary canine impaction in group I and group II. This table shows that there is no statistically significant difference $(P=0.79)$ in distribution of canine impaction in Group I (with maxillary transverse discrepancy) and Group II (without maxillary transverse discrepancy).

Table // shows the distribution of impacted maxillary canines according to sector classification in group I and group II. In order to describe the distribution of impacted maxillary canines more

Table I

Distribution of maxillary canine impaction in Group I and Group II.

\begin{tabular}{|lcc}
\hline Group & $\begin{array}{c}\text { No potential canine } \\
\text { impaction (sector I), } \boldsymbol{n}(\%)\end{array}$ & $\begin{array}{c}\text { Potential canine } \\
\text { impaction (sector II, III, IV), } \boldsymbol{n}(\%)\end{array}$ \\
$\begin{array}{l}\text { Group I (with maxillary transverse discrepancy) } \\
\begin{array}{l}n=46\end{array}\end{array}$ & $19(41.3)$ & $27(58.7)$ \\
$\begin{array}{l}\text { Group II (without maxillary transverse discrepancy) } \\
n=39\end{array}$ & $15(38.5)$ & $24(61.5)$ \\
\hline Total observations & $34(40)$ & $51(60)$ \\
\hline
\end{tabular}

$n=85$. Chi-square test.

" $P$-value $<0.05$. 
To cite this article: Ghaffar F, et al. Association between maxillary transverse discrepancy and occurrence of potentially impacted maxillary canines in mixed dentition patients. International Orthodontics (2019), https://doi.org/10.1016/j.ortho.2019.06.016

Association between maxillary transverse discrepancy and occurrence of potentially impacted maxillary canines in mixed dentition patients

TABLE II

Distribution of impacted maxillary canines according to sector classification in Group I and Group II.

\begin{tabular}{|c|c|c|c|}
\hline \multirow[t]{2}{*}{ Sector classification right (R) to left (L) } & \multicolumn{3}{|c|}{ Groups } \\
\hline & $\begin{array}{c}\text { Group I (with maxillary transverse } \\
\text { discrepancy) } \\
n=46, n(\%)\end{array}$ & $\begin{array}{l}\text { Group II (without maxillary transverse } \\
\text { discrepancy) } \\
n=39, n(\%)\end{array}$ & $\begin{array}{c}\text { Total } \\
n=85\end{array}$ \\
\hline I (no potential impaction) & $19(41.3)$ & $15(38.5)$ & 34 \\
\hline II $\mathrm{R}$ & $10(21.7)$ & $6(15.4)$ & 16 \\
\hline II L & $11(24)$ & $8(20.5)$ & 19 \\
\hline II \& II & $6(13)$ & $8(20.5)$ & 14 \\
\hline II \& IV & $0(0)$ & $1(2.5)$ & 1 \\
\hline III \& II & $0(0)$ & $1(2.5)$ & 1 \\
\hline Total & $46(100)$ & $39(100)$ & 85 \\
\hline
\end{tabular}

TABLE III

Distribution of unilateral and bilateral potential maxillary canine impaction in Group I and Group II.

\begin{tabular}{|c|c|c|c|}
\hline Groups & Unilateral impaction, $n(\%)$ & Bilateral impaction, $\boldsymbol{n}(\%)$ & $P$-value \\
\hline $\begin{array}{l}\text { Group I (with maxillary transverse discrepancy) } \\
n=46\end{array}$ & $21(46)$ & $6(13)$ & 0.135 \\
\hline $\begin{array}{l}\text { Group II (without maxillary transverse discrepancy) } \\
n=39\end{array}$ & $14(36)$ & $10(26)$ & \\
\hline $\begin{array}{l}\text { Total observations } \\
n=85\end{array}$ & 35 & 16 & \\
\hline
\end{tabular}

$\Pi=85$. Chi-square test.

"P-value $<0.05$.

comprehensively between both the group-combinations of sector classification were made for the right and left side. Unilateral impactions in both the groups are seen in sector II only, with $41.2 \%$ of our study sample showing a potentially impacted unilateral maxillary canine. The most frequent bilateral potential maxillary canine impaction was also seen in sector II, with six patients in Group I and eight patients in Group II exhibiting this malocclusion.

Toble III shows the distribution of unilateral and bilateral potential maxillary canine impaction in both the groups and depicts that there was no significant difference $(P=0.13)$ found in the distribution of unilateral and bilateral potential maxillary canine impaction in both the groups.

\section{Discussion}

Recognizing early canine displacement and predicting its failure to erupt in the arch is one of the fundamental aspects in the management of an impacted permanent maxillary canine. Potentially impacted maxillary canines using various diagnostic parameters are usually identified on a panoramic film. Similarly, in the current study, orthopantomograph was used to predict potential maxillary canine impaction in the early mixed dentition stage using sector classification. Warford et al. [11] reported sector location to be the best predictor for canine impaction. Schindel and Duffy [25] also used sector as a predictor for potential maxillary canine impaction and reported that potential maxillary canine impactions were seen in sectors II, III or IV. Likewise, Lindauer et al. [23] reported that 78\% of their total study sample fell in sector II, III and IV. Warford et al. [11] found similar results with $82 \%$ of impacted canines were found in sectors II to IV. Based on the above studies [11,23,25], a canine was classified as impacted if it was located in sectors II, III or IV. Based on the results of the above studies $[11,23,25]$, sector classification was used as a predictor for potential canine 
To cite this article: Ghaffar F, et al. Association between maxillary transverse discrepancy and occurrence of potentially impacted maxillary canines in mixed dentition patients. International Orthodontics (2019), https://doi.org/10.1016/j.ortho.2019.06.016

F. Ghaffar, R.H. Sukhia, M. Fida

impaction on orthopantomographs in the current study. In our study out of a total of 170 maxillary canines $60 \%$ were seen to fall in sector II, III and IV and therefore, being classified as potentially impacted. Based on their study results, Warford et al. [11] concluded that maxillary canines falling in sector I would not be impacted and are therefore not clinically significant. Canines falling in sector III and IV were destined to be impacted and would ultimately require surgical exposure. However, canines found in sector II had potential to become impacted and any interceptive procedure undertaken during mixed dentition stage like extraction of deciduous canine or expansion of arch would prevent future impaction, thus saving future time, cost and complicated surgical procedures. In our study $41.3 \%$ of the canines in Group I (with maxillary transverse discrepancy) and 38.5\% of the canines in Group II (no maxillary transverse discrepancy) were in Sector I, indicating no potential for impaction. The percentage of canines falling into Sector III and IV was only 5\% in the Group II (no maxillary transverse discrepancy) subjects. No canines were found to be in Sector III and IV in the Group I (with maxillary transverse discrepancy) subjects. An association was reported between maxillary transverse deficiency and maxillary canine impaction by McConnell et al. [22]. Their results showed that intercanine arch width was deficient in patients with maxillary canine impactions compared with controls. There was no difference in the intermolar arch widths between the two groups. Similarly other studies [25-27] have also reported potentially impacted canines in patients with maxillary transverse discrepancy.

However, in contrast to the above study, our study results depicted that there was no significant association between maxillary transverse discrepancy and occurrence of potentially impacted maxillary canines $(P=0.79)$. Similar results have been reported in the literature, where transverse dimensions of the maxilla have not been significantly associated with palatably impacted canines $[28,29]$. In the current study the mean age of the patients with maxillary transverse discrepancy was 9.9 years and the patients without maxillary transverse discrepancy had a mean age of 10.2 years. The patients having maxillary transverse discrepancy had mean maxillary intermural width of $38.8 \mathrm{~mm}$ with mean mandibular intermural width of $40.7 \mathrm{~mm}$. The mean transverse discrepancy computed between the maxilla and the mandible in our study group was $-1.9 \mathrm{~mm}$. Similarly, Lang erg and Peck [4] that there was no maxillary transverse discrepancy in subjects presenting with palatal canine impactions. Based on their study results, Lang erg and Peck [4] argued that in McConnell et al.'s [22] study the precise position of the impacted maxillary canines was not identified. McConnell et al. [22] attempted to predict the site of eruption of the maxillary canine in the dentoalveolar arch. Both the above studies $[4,22]$ measured maxillary widths on dental casts. In order to avoid further radiation exposure of posteroanterior radiographs, the current study also used dental casts for measuring maxillary and mandibular intermolar widths. Since in above studies $[4,22]$ dental casts were used to evaluate the transverse discrepancy therefore the association between actual transverse skeletal discrepancy with maxillary canine impactions cannot be commented upon. This was also the limitation of the current study, as we could not select our patients according to skeletal transverse discrepancy based on posteroanterior cephalographs. However in contrast to the above study [4], Schindel and Duffy [25] found an association between potentially impacted maxillary canines and maxillary transverse discrepancy in mixed dentition patients. In their study they predicted that there were significantly less 'no canine impactions' in the maxillary transverse deficiency group (46.4\%) compared with the non deficient group (81\%). In contrast, our study results depict no significant difference $(P=0.79)$ in the occurrence of no canine impactions (41.3\%) in the maxillary transverse discrepancy group when compared with the subjects having no canine impactions (38.5\%) without maxillary transverse discrepancy. Sambataro et al. [2] and McConnell et al. [22] reported that approximately $8 \%$ of the impactions were bilateral canine impactions. Similarly, Schindel and Duffy [25] concluded in their study, that the experimental group constituted of $80 \%$ unilateral and 20\% bilateral impacted canines. Whereas 74\% were unilateral and $26 \%$ were bilateral canine impactions in the control group. On the basis of their study results they concluded that unilateral impactions were more commonly found in patients with maxillary transverse discrepancy.

In agreement with the above studies [1,22,25], our findings depict that the patients with maxillary transverse discrepancy had 46\% unilateral impactions and 13\% bilateral impactions. Similarly patients without maxillary transverse discrepancy showed 36\% unilateral and 26\% bilateral impactions. Thus on the basis of these results, the present study concludes that patients irrespective of maxillary transverse discrepancy are seen to have more potential maxillary unilateral impactions than bilateral impactions.

Schindel and Duffy [25] computed the percentage of sector combinations for unilateral impacted canines (right and left canine sector classification) and reported $97.2 \%$ and $2.8 \%$ of the unilaterally impacted canines, in the transverse deficiency group, to be found in Sector II and IV respectively. For the nondeficient group, $78.6 \%$ and $21.4 \%$ of the unilateral impacted canines were found in Sector II and Sector III respectively. Our study results also depict the percentage of sector combinations for unilaterally impacted canines (right canine sector classification, left canine sector classification) and found that for the patients with or without maxillary transverse discrepancy, all unilaterally impacted canines were in sector II and none of the unilateral canines were observed in sector III or IV.

As far as the percentage of sector combinations with regards to right and left sides, for bilateral canine impactions for both groups in our study is concerned, sector "II, II" was most 
commonly seen in both the groups followed by "II, IV" and "III, II" in the group without maxillary transverse discrepancy. No other sector combination for bilateral canine impaction was observed in patients with maxillary transverse discrepancy. Similarly, Schindel and Duffy [25] found the sector combination "II, II" to be most common in both the groups in their study. In their experimental group, $22.2 \%$ were located in sector combination "III, II" and 11.1\% were located in sector combination "IV, III". For the control group, 40\% were located in sector combination "II, III". In our study, for group I (with maxillary transverse discrepancy) the percentage for sector "II R" was 21.7\%, for sector "II L" was 24\% and for sector combination "II, II" was 13\%. No other sector combinations occurred for group I. Whereas for group II (without maxillary transverse discrepancy), percentage for sector "II R" was $15.4 \%$, for sector "II L" was $20.5 \%$, percentage for sector combination "II, II" was 20.5\%, for sector "III, II" and "II, IV" was $2.5 \%$ respectively. No other sector combination occurred in the control group II.

Early mixed dentition is the best time to diagnose a potentially impacted canine. This is the time when the canine starts to descend in the arch. Presently, various modalities including extracting deciduous canines and expanding a constricted maxillary arch are commonly used to prevent potential maxillary canine impaction [7].

Ericson and Kurol [7] found that a normal eruption of the maxillary canine is seen in 78\% of palatally displaced canines after extracting the deciduous canine. Mcconnell et al. [22] also recommend orthopedic expansion of the maxilla to aid in intercepting palatally erupting canines to a proper position in the arch.

The diagnostic accuracy of three dimension-computed tomography in assessment of impacted canines has been shown to range between 50 and $90 \%$ as compared to orthopantomogram, which ranges between 39 and 85\% [30]. It is therefore recommended that further studies may be carried out using this three-dimensional technique for better accuracy.

Based on this study, it is important to be aware of potential maxillary canine impaction in the presence or absence of transverse maxillary discrepancy in the mixed dentition stage. The radiographic presence of the canine in sector II, III, or IV presents a high risk of canine impaction. It is therefore recommended that in future studies may be carried out to evaluate the effectiveness of deciduous canine extraction and maxillary orthopedic expansion in cases of maxillary transverse discrepancy with a potential of canine impaction. Also, occlusal radiograph or CBCT may serve as a useful diagnostic tool for future studies [23].

\section{Conclusion}

There was no significant association between maxillary transverse discrepancy and occurrence of potentially impacted maxillary canines in mixed dentition patients, thus indicating that patients having maxillary transverse discrepancy in the mixed dentition may not be at a higher risk of palatal canine impaction. Radiological presence of canine in sector II, III and IV, pose a higher risk of canine impaction.

Funding: this study was funded by University Research Council Grant from Q3 the Aga Khan University, Karachi, Pakistan. Grant number: 08GS0036SUR.

Disclosure of interest: the authors declare that they have no competing interest.

\section{References}

[1] Sambataro S, Baccetti T, Franchi L, Antonini F. Early predictive variables for upper canine impaction as derived from posteroanterior cephalograms. Angle Orthod 2005;75:28-34.

[2] Shapira Y, Kuftinec MM. Early diagnosis and interception of potential maxillary canine impaction. J Am Dent Assoc 1998;129:1450-4.

[3] Coulter J, Richardson A. Normal eruption of the maxillary canine quantified in three dimensions. Eur J Orthod 1997;19:171-83.

[4] Langberg BJ, Peck S. Adequacy of maxillary dental arch width in patients with palatally displaced canines. Am J Orthod Dentofacial Orthop 2000;118:220-3.

[5] Langberg BJ, Peck S. Tooth-size reduction associated with occurrence of palatal displacement of canines. Angle Orthod 2000;70:126-8.
[6] Ericson S, Kurol J. Early treatment of palatally erupting maxillary canines by extraction of the primary canines. Eur J Orthod 1988; 10:283-95

[7] Kuftinec MM, Shapira Y. The impacted maxillary canine: I. Review of concepts. ASDC J Dent Child 1995:62:317-24.

[8] Mulick JF, James F. Mulick on impacted canines. J Clin Orthod 1979;13:824-34.

[9] Ericson S, Kurol J. Radiographic examination of ectopically erupting maxillary canines. Am J Orthod Dentofacial Orthop 1987;91:483-92.

[10] Power SM, Short MB. An investigation into the response of palatally displaced canines to the removal of deciduous canines and an assessment of factors contributing to favourable eruption. Br J Orthod 1993:20:215-23.

[11] Warford Jr JH, Grandhi RK, Tira DE. Prediction of maxillary canine impaction using sectors and angular measurement. Am J Orthod Dentofacial Orthop 2003;124:651-5.

[12] Abron A, Mendro RL, Kaplan S. Impacted permanent maxillary canines: diagnosis and treatment. N Y State Dent J 2004;70:24-8.

[13] Bishara SE. Impacted maxillary canines: a review. Am J Orthod Dentofacial Orthop 1992:101:159-71.

[14] Alessandri Bonetti G, Zanarini M, Incerti Parenti S, Marini I, Gatto MR. Preventive treatment of ectopically erupting maxillary permanent canines by extraction of deciduous canines and first molars: a randomized clinical trial. Am J Orthod Dentofacial Orthop 2011;139:316-23.

[15] Baccetti T, Sigler LM, McNamara Jr JA. An RCT on treatment of palatally displaced canines with RME and/or a transpalatal arch. Eur J Orthod 2011;33:601-7. 
To cite this article: Ghaffar $\mathrm{F}$, et al. Association between maxillary transverse discrepancy and occurrence of potentially impacted maxillary canines in mixed dentition patients. International Orthodontics (2019), https://doi.org/10.1016/j.ortho.2019.06.016

F. Ghaffar, R.H. Sukhia, M. Fido

둔

[16] Bishara SE, Kommer DD, McNeil MH, Montagano LN, Oesterle LJ, Youngquist HW. Management of impacted canines. Am J Orthod 1976;69:371-87.

[17] Becker A, Smith P, Bihar R. The incidence of anomalous maxillary lateral incisors in rebatimon to palatally-displaced cuspids. Angle Orthod 1981;51:24-9.

[18] Jacobs $H$. The etiology of maxillary canine impactions. Am J Orthod 1983;84:125-32.

[19] Peck S, Peck L, Kataja M. Prevalence of tooth agenesis and peg-shaped maxillary lateral incisor associated with palatally displaced canine (PDC) anomaly. Am J Orthod Dentofarial Orthop 1996;110:441-3.

[20] Fournier A, Turcotte JY, Bernard C. Orthodontic considerations in the treatment of maxillary impacted canines. Am J Orthod 1982;81:236-9.

[21] McNamara JA. Maxillary transverse deficiency. Am J Orthod Dentofacial Orthop 2000;117:567-70.
[22] McConnell TL, Hoffman DL, Forbes DP, Janzen EK, Weintraub NH. Maxillary canine impacton in patients with transverse maxillary deficiency. ASDC J Dent Child 1996;63:190-5.

[23] Lindauer SJ, Rubinstein LK, Hang WM, Andersen WC, Isaacson RJ. Canine impaction identified early with panoramic radiographs. J Am Dent Assoc 1992;123:91-2 [95-7].

[24] Jung YH, kiang $H$, Benson BW, Flint DJ, Tho $\mathrm{BH}$. The assessment of impacted maxillary canine position with panoramic radiography and cone beam CT. Dentomaxillofac Radio 2012;41:356-60.

[25] Schindel RH, Duffy SL. Maxillary transverse discrepancies and potentially impacted maxillary canines in mixed-dentition patients. Angle Orthod 2007;77:430-5.

[26] Cacciatore G, Poletti L, Sforza C, Hong WH, Radfar R, Chung $\mathrm{CH}$. Early diagnosed impacted maxillary canines and the morphology of the maxilla: a three-dimensional study. Prog Orthod 2018;19:20.
[27] Oleo-Aracena D, Arriola-Guillén LE3 MF, Rodríguez-Cárdenas YA, Ruíz-Mora GA. Sheleal and dentoalveolar bilateral dimensions in unilateral palatably impacted canine using cone beam computed tomography. Prog Orthod 2017; 18:7.

[28] Hong WH, Radfar R, Chung CH. Relationship between the maxillary transverse dimension and palatally displaced canines: a cone-beam computed tomographic study. Angle Orthod 2015;85:440-5.

[29] Yam B, Sun Z, Fields H, Wang L, Lu L. Etiologic factors for buccal and palatal maxillary canine impaction: a perspective based on cone-beam computed tomography analyses. Am J Orthod Dentofacial Orthop 2013;143:527-34.

[30] Amintavakoli N, Spivakovsky S. Cone-beam computed tomography or conventional radiography for localising of maxillary impacted canines? Evid Based Dent 2018;19:22-3.

$\infty$

tome $x x>000>x x 2019$

ARTICLE IN PRESS 